\section{Justice, disparities and the tobacco endgame}

\author{
Ruth E Malone
}

People working in the field have long talked about tobacco as a social justice issue, but considerations of just what to do about addressing that have often been secondary to identifying and documenting the numerous disparities that persist between groups with social advantages and those without. In a sense, this is understandable: for some disadvantaged populations, it has been a real fight to simply become recognised and visible enough to have data systematically collected for research. For others, it has been a struggle to articulate within their own communities why tobacco has something to do with the overarching systemic injustices that permeate daily life. This issue features a set of papers that speak broadly to the theme of tobacco and social justice, demonstrating how researchers are thinking about these issues in work that moves the field forward.

Titus et $a l^{1}$ conducted a study using census data to explore disparities in smoking rates and exposure to tobacco control policies (smoke-free laws and televised anti-tobacco campaigns) among sexual minority adults. They found that while there were no differences in exposure to televised campaigns, sexual minority adults were actually more likely to live in counties with strong smokefree policies, suggesting that other factors are contributing to higher smoking rates among these groups. Shokoohi et al's ${ }^{2}$ review, meta-analysis and meta-regression shows why it is important to think carefully about HOW we analyse and interpret the data we do collect. Their study demonstrates that bisexuals (and in particular, bisexual women) have higher cigarette smoking rates than gays/lesbians. For many years, data on sexual orientation were not collected at all, and even after they began to be included, studies often combined these groups into an 'LGB' (lesbian, gay and bisexual) category despite important differences between them. This review suggests that the intersection (or interaction) of sexual orientation and gender/sex may contribute to higher rates of cigarette use, pointing to the need for data disaggregation in order

Correspondence to Professor Ruth E Malone, Social and Behavioral Sciences, University of California, San Francisco, CA 94143, USA; ruth.malone@ucsf.edu to better target public health interventions for specific groups.

In addition to sexual orientation, these intersectional disadvantages may also include income, race, class and educational levels, and each can affect overall health. In a population sample, Jackson et $a l^{3}$ found that current smoking was independently associated with self-reported confirmed COVID-19 infection. There were, however, socioeconomic disparities, with the association only apparent among those with lower educational levels.

An important part of the global conversation about planning for a tobacco endgame, then, is how to ensure that the groups with highest smoking rates, who generally also have other forms of disadvantage with which to contend, are not ignored or left behind. One might consider, for example, that in Panama, the country with the lowest overall reported tobacco use prevalence in the Americas, the endgame battle is basically won. But this would be wrong. In one of the small number of such studies, Quintana and $\mathrm{Roa}^{4}$ highlight that among indigenous Panamanian adolescents, current tobacco use is almost twice the national average and discuss some possible reasons why.

Similarly, a Canadian study examining changes in secondhand smoke exposure before, during and after a 2015 population tobacco control measure that extended smoke-free laws found that among groups of different income and education levels, exposures among all groups decreased across time periods but the magnitude of inequalities in exposure did not change. ${ }^{5}$

Given these persistent disparities, it is important to consider prioritising public health interventions that not only reduce smoking overall, but also contribute to reducing the disparities themselves. Smith et $a l^{6}$ conducted a review on the equity impacts of population-level tobacco control interventions and found mixed results. Price increases and targeted population-level cessation support were the only interventions where there was a clear positive equity impact (effects were greatest among low socioeconomic status individuals).

While it is good news that price increases have clear and favourable equity impacts, few studies have explored whether this holds true for remote indigenous communities known to have higher than average rates of smoking. Thomas et $\mathrm{al}^{7}$ analysed 3 years of retail sales data from stores in remote Aboriginal communities in Australia to determine the effects of price increases following successive tax increases. They demonstrate for the first time that price increases are indeed effective in reducing sales in such remote communities, but also identify the need to harmonise tax/price for products like rollyour-own tobacco.

Still, as another study in this collection shows, ${ }^{8}$ those positive impacts may be attenuated by how they are perceived and responded to by affected communities. Engaging indigenous Māori (New Zealand) whānau units in open-ended discussions, Gifford et al identified practices used among families to resist the intended effects of government tax increases, such as sharing products, taking turns purchasing and other similar practices. The tax increases were perceived negatively as externally imposed, not part of a Maori initiative to improve community health. This work points to the importance of fully engaging communities most impacted by tobacco in designing public health policies and plans consistent with community values.

The well-known 'Tobacco Control Vaccine' model (comprising price increases, smoke-free policies, hardhitting media campaigns and cessation resources) is extended with a 'booster' in an analysis by Kong and King ${ }^{9}$ which highlights the retail environment, the topic of another set of interesting papers in this issue that further extends the growing literature on the role of tobacco retailers in tobacco disparities. Craigmile et $a l^{10}$ contribute to the rapidly expanding literature on tobacco retailer density and numbers, demonstrating through simulation modelling that different approaches to regulating retailers through zoning, capping, declustering and other strategies could have differential effects depending on type of community, decreasing or increasing disparities. Caryl et $a l^{11}$ report similar findings from a study of tobacco retail density in Scotland, finding that depending on the approach to retailer density reduction, policies could have the negative consequence of increasing socioeconomic disparities in tobacco outlet density. Trapl et $a l^{12}$ find an association between tobacco retailer exposure and adolescent smoking: those who walked to school and stopped at retailers were more likely to use tobacco products.

Finally, Mills et $a l^{13}$ offer practical lessons in why it is crucial to invest time 
in building trusting relationships across communities affected by social, economic and racial inequities before asking them to support policy change. The African American Tobacco Control Leadership Council grew from the passion and determination of a handful of dedicated individuals to become a nationally recognised leader in efforts to end sales of menthol products. In this Advocacy in Action piece, lessons learnt in passing a policy ending sales of all flavoured tobacco products in San Francisco, California, USA show how leading by listening is the secret sauce of powerful coalitions.

Twitter Ruth E Malone @MaloneRuth

Funding The authors have not declared a specific grant for this research from any funding agency in the public, commercial or not-for-profit sectors.

Competing interests https://tobaccocontrol.bmj. com/pages/wp-content/uploads/sites/49/2021/08/RuthMalone-DOI-2021.pdf

Patient consent for publication Not required.

Ethics approval This study does not involve human participants.

Provenance and peer review Not commissioned; internally peer reviewed.
(C) Author(s) (or their employer(s)) 2021. No commercial re-use. See rights and permissions. Published by BMJ.

\section{Check for updates}

To cite Malone RE. Tob Control 2021:30:e76-e77.

Tob Control 2021;30:e76-e77.

doi:10.1136/tobaccocontrol-2021-057188

ORCID iD

Ruth E Malone http://orcid.org/0000-0002-3324-2183

\section{REFERENCES}

1 Titus AR, Gamarel KE, Thrasher JF, et al. Are sexual minority adults differentially exposed to smoke-free laws and televised anti-tobacco media campaigns compared to the general US population? A descriptive analysis. Tob Control 2021;e2:e154-7.

2 Shokoohi M, Salway T, Ahn B, et al. Disparities in the prevalence of cigarette smoking among bisexual people: a systematic review, meta-analysis and metaregression. Tob Control 2021;e2:e78-86.

3 Jackson SE, Brown J, Shahab L, et al. COVID-19, smoking and inequalities: a study of 53002 adults in the UK. Tob Control 2021;e2:e111-21.

4 Quintana H, Roa R. Tobacco use and access among 13 to 15 year olds in Kuna Yala, an indigenous region of Panama. Tob Control 2021;e2:e158-67.

5 Gagné T, Lapalme J, Ghenadenik AE, et al. Socioeconomic inequalities in secondhand smoke exposure before, during and after implementation of
Quebec's 2015 'An Act to Bolster Tobacco Control'. Tob Control 2021:e2:e128-37.

6 Smith CE, Hill SE, Amos A. Impact of population tobacco control interventions on socioeconomic inequalities in smoking: a systematic review and appraisal of future research directions. Tob Control 2021;e2:e87-95.

7 Thomas DP, McMahon E, Wang Z, et al. Impact of three annual tobacco tax rises on tobacco sales in remote Australian Aboriginal community stores. Tob Control 2021;e2:e122-7.

8 Gifford H, Waa A, Cvitanovic L, et al. Exploring indigenous perspectives on tobacco tax: how some Māori families are responding in Aotearoa New Zealand. Tob Control 2021;e2:e144-9.

9 Kong AY, King BA. Boosting the tobacco control vaccine: recognizing the role of the retail environment in addressing tobacco use and disparities. Tob Control 2021;e2:e62-8.

10 Craigmile PF, Onnen N, Schwartz E, et al. Evaluating how licensing-law strategies will impact disparities in tobacco retailer density: a simulation in Ohio. Tob Control 2021;e2:e96-103.

11 Caryl FM, Pearce J, Reid G, et al. Simulating the density reduction and equity impact of potential tobacco retail control policies. Tob Control 2021;e2:e138-43.

12 Trapl E, Anesetti-Rothermel A, Pike Moore S, et al. Association between school-based tobacco retailer exposures and young adolescent cigarette, cigar and e-cigarette use. Tob Control 2021;e2:e104-10.

13 Mills SD, McGruder CO, Yerger VB. The African American Tobacco Control Leadership Council: Advocating for a menthol cigarette ban in San Francisco, California. Tob Control 2021;e2:e150-3. 